\title{
Levantamento de vertebrados silvestres mortos por atropelamento em ro- dovia estadual do Brasil
}

\author{
Cleverson Danrley Cruz Dias ${ }^{\mathrm{a}^{*}} \oplus$, Sâmia Marília Câmara Lopes $^{\mathrm{a}}{ }^{\oplus}$, Hellen José Daiane Alves Reis ${ }^{\mathrm{a}}$ \\ a Universidade Federal do Maranhão, Brasil \\ *Autor correspondente (cleverson_55dias@hotmail.com)
}

\section{N F O}

\section{Keyworks}

re-trampling

seasonality

death of animals

mitigation measures

\begin{abstract}
A B S T R A C T
Survey of wild vertebrates killed by run over on a Brazilian state highway

The roads and highways represent a great advance for the humanity development. Despite this, the construction of highways is one of the human actions with a great impact on the natural environment, such as the run over of wild animals. The objective of this work was to quantify and identify the wild vertebrate animals run over on the state highway MA-106, specifically the lenght that connects the cities of Santa Helena and Pinheiro. The methodology used for this work was the field research with survey of quantitative data. The carcasses of the found animals were photographed, each carcass was georeferenced, as well as recorded in data sheets, and carcass re-run over was also evaluated. 41 species were found, with a total of 16 different vertebrate species. The reptile class was the most affected with $43.90 \%$ records and six species, and the less affected class was the amphibian with $4.88 \%$ records and two species. During the study, there was no seasonality in the monthly run over rate for mammals and amphibians, while the birds group had a higher incidence in the less rain period. For reptiles, the highest incidence occurred during the period of rainfall. Ultimately, after analyzing the collected data, it is perceive that some mitigation measures can be implemented to minimize the run overs, such as an adequate fauna signaling, methods that difficult animals to cross the highways and devices that facilitate fauna crossing roads.
\end{abstract}

\section{R E S U M O}

As estradas e rodovias representam um grande avanço para o desenvolvimento da humanidade. Apesar disso, a criação das rodovias é uma das ações humanas de grande impacto sobre o ambiente natural como o caso de atropelamentos de animais silvestres. Assim, o objetivo deste trabalho foi quantificar e identificar os animais vertebrados silvestres atropelados na rodovia estadual MA-106, especificamente o trecho que liga as cidades de Santa Helena e Pinheiro. A metodologia utilizada foi a pesquisa de campo com levantamento de dados quantitativos. Foram fotografadas as carcaças dos animais encontrados, feito o georreferenciamento de cada carcaça bem como registrados em planilhas de dados, e foi verificado o reatropelamento das carcaças. Foram registrados 41 espécimes com o total de 16 espécies distintas de vertebrados. A classe dos répteis foi a mais afetada com $43,90 \%$ dos registros e 06 espécies e a classe menos afetada foi a dos anfíbios com $4,88 \%$ dos registros e 02 espécies. Durante o estudo não foi encontrada sazonalidade na taxa mensal de atropelamento para mamíferos e anfíbios, já o grupo das aves apresentou um número maior de incidência no período com menor número de chuva. Para os répteis o número maior de incidência ocorreu no período de maior número de chuvas. Por fim, após análise dos dados coletados, nota-se que certas medidas de mitigação podem ser implantadas para minimizar os atropelamentos, como por exemplo uma sinalização de fauna adequada, meios que dificultem a travessia de animais nas rodovias e dispositivos facilitadores de travessia de fauna. 


\section{INTRODUÇÃO}

As estradas e rodovias representam uma grande relevância para o desenvolvimento da humanidade, pois além de permitirem a movimentação de diversos produtos são a conexão entre centros urbanos e rurais, concebendo as principais vias de deslocamento de pessoas e cargas. Apesar disso, a criação das rodovias é uma das ações humanas de grande impacto sobre o ambiente natural (Bandeira e Floriano, 2004). Um dos problemas mais evidentes na fauna, gerados pelo estabelecimento e funcionamento de rodovias, é a morte de animais silvestres causadas pelo choque com veículos (Deffaci et al., 2016).

O Brasil, possui uma área de mais de 8,5 milhões de $\mathrm{km}^{2}$, (IBGE, 2012). Assim, sendo preciso interligar todos esses pontos, fez-se necessário criar uma extensa malha de rodovias pavimentadas e não pavimentadas que somavam no ano de 2017, 1,53 milhões de quilômetros (Ministério Dos Transportes - MT, 2018). Segundo Sant'ana (2009), o Estado do Maranhão dispõe de uma rede de aproximadamente $55.000 \mathrm{~km}$ de estradas e rodovias, tendo em sua grande maioria volumes médios diários inferiores a 400 veículos. Dos $55.000 \mathrm{~km}$ de rodovias do Maranhão, $3.464 \mathrm{~km}$ são federais, $5.161 \mathrm{~km}$ são estaduais e $44.376 \mathrm{~km}$ municipais (Transportes no Maranhão, 2000).

Estradas e rodovias podem ocasionar separação e fragmentação de ambientes e "obrigar" populações de animais a atravessá-las. Tal fato amplia a possibilidade de colisão da fauna com automóveis (Trombulak e Frissell, 2000). Esta tem sido indicada como a mais evidente causa de letalidade de vertebrados por atuação direta de atividades antrópicas no Brasil e no mundo (Bager et al., 2016).

O óbito de animais silvestres (segundo descreve $\mathrm{o}$ art. $1^{\circ}$ da Lei $\mathrm{n}^{\mathrm{o}} 5.197 / 67$, identifica-se fauna silvestre o agrupamento de animais que vivem em liberdade, fora do cativeiro) por atropelamento é um problema ainda pouco destacado entre os problemas que ameaçam a biodiversidade faunística brasileira. O total de animais mortos nas rodovias e estradas brasileiras todo ano pode ser significativo. Entretanto, ainda são limitados os estudos de extensa duração e as exposições sobre o tema. Publicações expondo o atropelamento de animais silvestres no país vieram somente a partir de 1998 (Santos et al., 2012).

Segundo Paes e Povaluk (2012) dentre os animais silvestres que mais são acometidos com os atropelamentos, sobressaem-se os mamíferos de médio e grande porte, o que pode ser reativo as suas necessidades de extensas áreas de vida e eficácia de efetuarem grandes deslocamentos. A travessia de animais pelas estradas, está correlacionada com diferentes necessidades como: migração, procura de alimentos ou simplesmente ocupação de territórios (Faria e Moreni, 2000), deixando assim esses animais ao risco de atropelamento por veículos automotores.

Carvalho (2014) destaca que a pesquisa da fauna silvestre atingida por atropelamentos nas estradas, fundamenta-se em um meio indispensável de informações acerca desse tipo de impacto, que pode também ser usada para contabilizar, de maneira indireta, algumas espécies endêmicas de uma dada região, no lugar em que há acúmulos de atropelamentos e que elementos os induzem. Além disso, informações associadas aos atropelamentos, como posição geográfica, topografia, paisagem de entorno, relevo, peculiaridades da pista são relevantes para a tomada de providências referentes à mitigação dos atropelamentos.

Segundo Santos et al. (2012) a sazonalidade é um elemento variante para os números de mortalidade por atropelamentos, dado que essa variação decorre do táxon e do regime climático da região. Estes mesmos autores informam que a quantidade de atropelamentos varia de acordo com as estações do ano, de modo que grande parte dos trabalhos apontam os mamíferos de médio e grande porte como os mais afetados, independente da estação, por outro lado anfíbios são mais acometidos nas épocas de chuva. Os atropelamentos podem também ser instigados por atributos das paisagens, pelas situações das estradas, que podem possibilitar ou não a visualização do animal pelos motoristas, pela falta de sinalização adequada, bem como, pela velocidade dos veículos (Prada, 2004).

A área de estudo deste trabalho encontra-se em uma porção da Baixada Maranhense. Esta, fica inserida no Bioma Amazônia, no Setor Oriental, sendo parte da Amazônia Legal Brasileira. Possui o maior conjunto de bacias lacustres do Nordeste brasileiro, incorporando complexa interface de ecossistemas, que abriga ricas fauna e flora, aquática e terrestre (Roth e Scott, 1987). Sendo assim uma área com boa representação de diversos tipos de animais silvestres.

No Brasil estudos dirigidos para a ecologia de estradas são muito escassos (Miranda, 2007). No Maranhão, somente em poucas estradas foram estudados os atropelamentos de vertebrados, como na rota de acesso aos Lençóis Maranhenses, onde o índice de atropelamento nos $227 \mathrm{~km}$ do espaço estudado foi de 6,1 animais/km/ano (Miranda, 2007).

Dentro desse contexto, o objetivo geral deste trabalho é quantificar e identificar os animais vertebrados silvestres atropelados na rodovia estadual MA-106, especificamente o trecho que 
liga as cidades de Santa Helena e Pinheiro. Para tal, será realizada a pesquisa de campo, com fotografias e georreferenciamento das carcaças dos animais encontrados, para dar suporte ao levantamento de dados quantitativos. Com isso, espera-se ter um número maior de estudos e pesquisas voltadas para esse assunto, a fim de elevar o conhecimento sobre o tema abordado.

\section{MATERIAL E MÉTODOS}

A metodologia utilizada para a elaboração deste trabalho é conhecida como pesquisa de campo. Sendo assim é relevante destacar que essa pesquisa se caracteriza também como um levantamento de dados quantitativos do número de carcaças de animais mortos no decorrer do estudo. A pesquisa quantitativa tem como base à linguagem matemática para fundamentar com dados concretos as relações entre variáveis e as causas de um fenômeno (Fonseca, 2002).

\section{Descrição da área de estudo}

O trecho percorrido para o estudo liga as cidades de Santa Helena - MA a Pinheiro - MA e têm aproximadamente $42 \mathrm{~km}$ de extensão, com acostamento em alguns pontos, geometria ruim e quase não apresenta sinalização, a velocidade máxima permitida é de $80 \mathrm{~km} / \mathrm{h}$, mas não há radares que controlem essa velocidade, todos os tipos de veículos podem trafegar por essa rodovia, sem restrição (Figura 1).

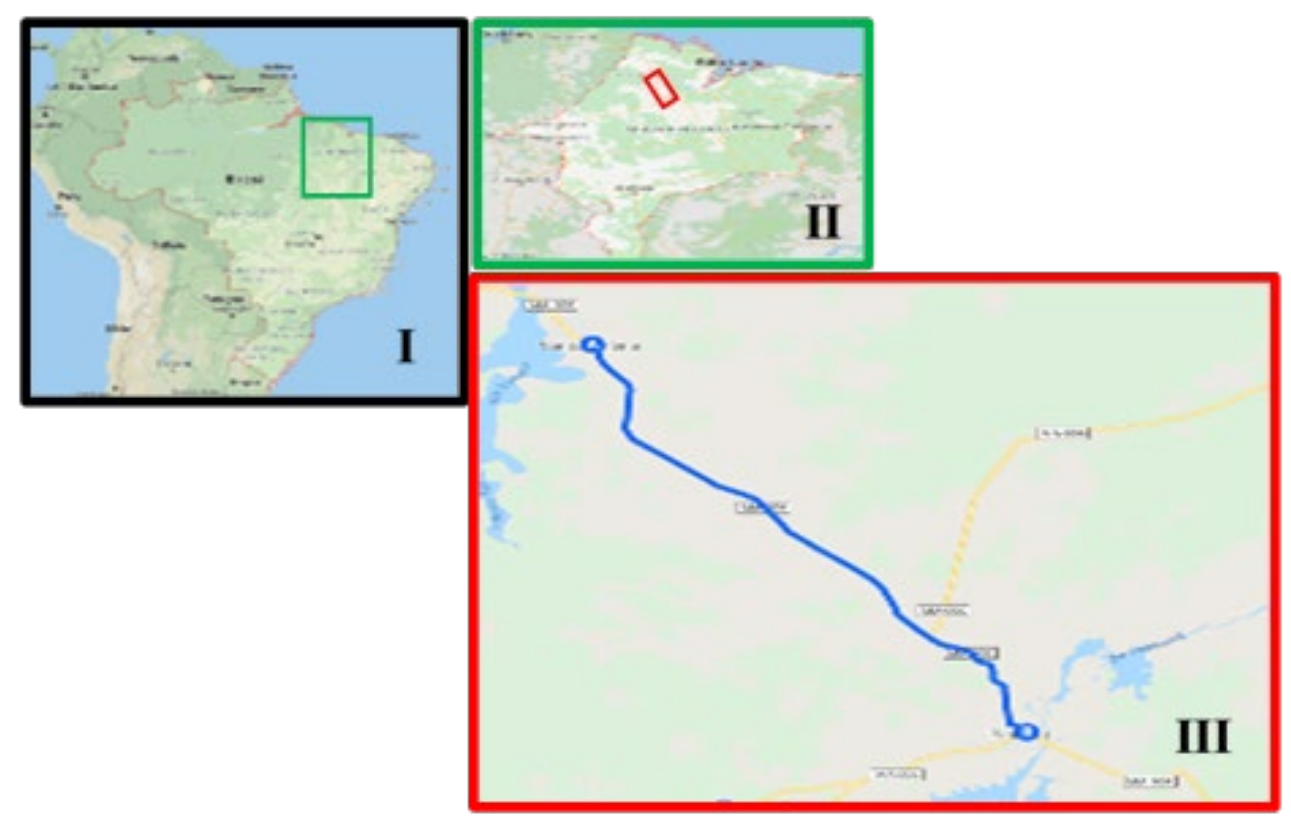

Figura 1 - Localização da área de estudo. I) Brasil; II) Estado do Maranhão; III) MA-106, trecho de Santa Helena a Pinheiro (Fonte: Google Maps, 2019)

\section{Coleta e análise dos dados}

A inspeção da rodovia foi feita com o auxílio de um veículo motorizado (motocicleta) a uma velocidade média de $50 \mathrm{~km} / \mathrm{h}$ a $60 \mathrm{~km} / \mathrm{h}$ no período de 14 de janeiro de 2019 a 16 de maio de 2019.

As viagens foram realizadas durante o período diurno, pois segundo Moreira et al. (2006), os atropelamentos ocorrem principalmente no período noturno; sendo assim, no período diurno as carcaças ainda estariam na rodovia.

No momento da localização de uma carcaça de animal, foram realizados registros fotográficos. Também foi feito o georreferenciamento de cada carcaça bem como registrados em planilhas de dados o início e fim de cada viagem, a quantidade de fotos tiradas de cada animal, se eles se encontravam na pista ou no acostamento, o cheiro e aspecto das carcaças, se havia ou não urubus e gaviões com as carcaças e se foram reatropeladas. Carcaças de animais domésticos não foram consideradas para os resultados.

Para este trabalho foi considerado reatropelamento a situação em que depois da morte do animal a permanência da carcaça na pista ocasionou outros atropelamentos à mesma, fato evidenciado pela observação do estado de algumas carcaças encontradas (achatadas sobre a pista, desfiguradas ou dilaceradas) (Figura 2). 


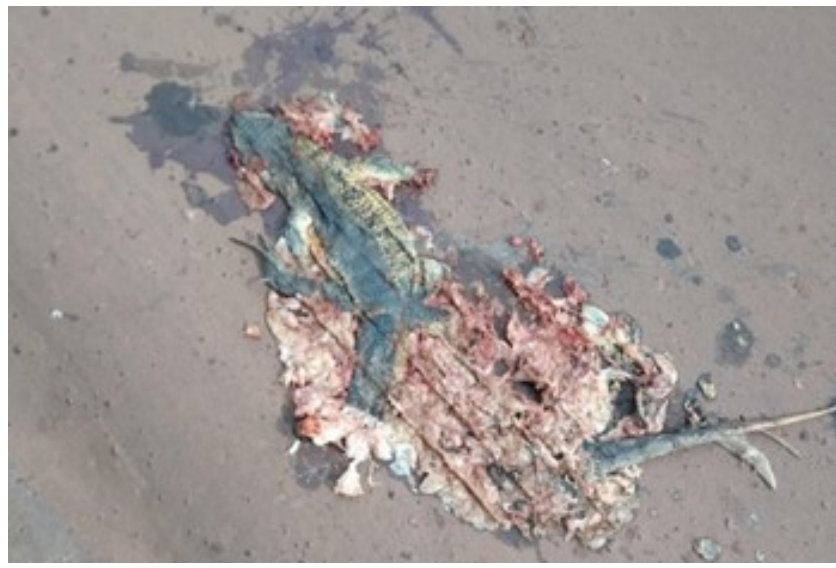

Figura 2 - Carcaça de lagarto na pista (possível evidenciar reatropelamentos).

Desta maneira foram realizadas considerações acerca do estado de decomposição, dividido em inicial: quando não apresentava cheiro característico de putrefação, e ainda era possível observar os músculos e sangue; intermediário: quando já apresentava cheiro forte e característico de putrefação; e avançado: também apresentando cheiro forte e característico de putrefação, mas já bem deformado por ação de decompositores por vezes apresentado só pele e ossos (Figura 3 ).

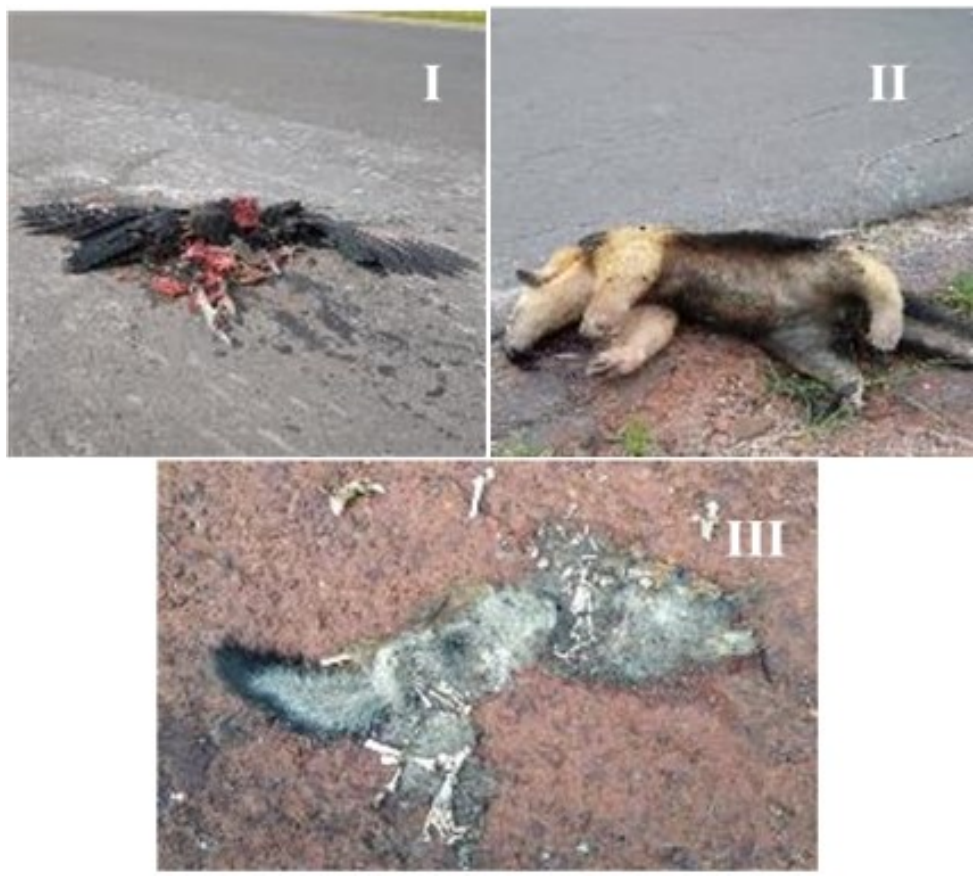

Figura 3 - Estágios de decomposição, I) Inicial; II) intermediário; III) avançado.

Os espécimes foram identificados posteriormente com base nas fotografias tiradas das carcaças pois não foram recolhidas para análise, e a comparação das imagens foi realizada com base em descrições, estudos, guias e chaves disponíveis para cada grupo na literatura: Répteis e Anfíbios (Bernarde et al., 2011), Aves (Maciel e Machado, 2013) e Mamíferos (Mesquita e Moraes, 2018).

\section{Análise estatística dos dados}

Após obter os dados, estes foram organizadas em tabelas com auxílio do programa editor de planilhas "Microsoft Office Excel 2013" para posteriores análises. O software "Google Earth Pro 2019" juntamente com a plataforma "Google Maps 2019" foram utilizados para a construção dos mapas utilizados neste trabalho. Os dados obtidos durante esta pesquisa foram analisados e discutidos segundo a literatura. 


\section{RESULTADOS E DISCUSSÃO}

$\mathrm{Na}$ determinação da estatística descritiva (Tabela 1) observa-se que o CV \% para todos os clones e seminal apresentaram variação baixa para variável $\mathrm{Ht}(\mathrm{m})$ e de média para DAP $(\mathrm{cm})$ de acordo com a classificação proposta por Warrick e Nielsen (1980), de baixa para CV $<12 \%$; média de $12 \%<\mathrm{CV}<60 \%$ e alta para $\mathrm{CV}>60 \%$. Sendo a maior variação para DAP justificada pela maior amplitude de seus dados.

Tabela 1 - Número de espécimes e porcentagem por espécie de vertebrados atropelados na Rodovia Estadual MA-106, trecho que liga os municípios de Santa Helena e Pinheiro, de janeiro de 2019 a maio de 2019.

\begin{tabular}{ccccc}
\hline Classe & Nome comum & Nome científico & $\mathbf{N}^{\mathbf{0}}$ de espécimes & $\mathbf{\%}$ \\
\hline \multirow{4}{*}{ Aves } & Urubu & Coragypus atratus & 5 & $12,20 \%$ \\
& Graúna & Sturnella superciliaris & 1 & $2,44 \%$ \\
& Anu-coroca & Crotophaga major & 1 & $2,44 \%$ \\
& Anu-preto & Crotophaga ani & 3 & $7,32 \%$ \\
& Bem te vi & Pitangus sulphuratus & 2 & $4,88 \%$ \\
& Sabiá-do-campo & Mimus saturninus & 1 & $2,44 \%$ \\
\hline \multirow{3}{*}{ Mamíferos } & Raposa-do-campo & Lycalopex vetulus & 2 & $4,88 \%$ \\
& Tamanduá-mirim & Tamandua tetradactyla & 2 & $4,88 \%$ \\
& Não identificados & Não identificados & 4 & $9,76 \%$ \\
\hline \multirow{4}{*}{ Répteis } & Iguana & Iguana iguana & 2 & $4,88 \%$ \\
& Lagarto - Teiú & Tupinambis teguixin & 4 & $9,76 \%$ \\
& Cobra-cipó & Chironius sp & 8 & $19,51 \%$ \\
& Jiboia & Boa constrictor & 1 & $2,44 \%$ \\
& Cobra-papa-pinto & Drymarchon corais & 2 & $4,88 \%$ \\
& Capininga & Trachemys adivtriz & 1 & $2,44 \%$ \\
\hline \multirow{2}{*}{ Anfíbios } & Sapo-cururu & Rhinella marina & 1 & $2,44 \%$ \\
& Cobra-cega & Amphisbaena alba & 1 & $2,44 \%$ \\
\hline Total & & & 41 & $100,00 \%$ \\
\hline
\end{tabular}

Este resultado difere da maioria das descrições feitas para estas quatro classes em outras regiões do país, onde geralmente, aves e mamíferos estão entre os dois grupos mais vitimados, e répteis e anfíbios são expostos como os menos registrados (Prada, 2004; Milli e Passamani, 2006; Almeida e Cardoso, 2014). Hengemühle e Cademartori (2008) destacam que essas alterações podem ser resultantes da metodologia de amostragem, de particularidades do trecho estudado, ou, ainda, de ambos.

Levando em consideração essas alterações, para este trabalho os resultados obtidos foram possíveis principalmente pelas particularidades do trecho de estudo, que é distinta das demais localidades do país onde trabalhos desse tipo foram realizados.

Embora essa discrepância dos resultados obtidos com outros trabalhos, em comparação ao levantamento de animais silvestres atropelados realizado por Mesquita e Moraes (2018), na rodovia $\mathrm{Br}-316$, entre o município de Caxias e Peritoró no estado do Maranhão, foram registrados 61 espécimes de animais silvestres atropelados, sendo que 28 pertenciam a classe dos répteis, desse modo apresentando resultados semelhantes a este estudo.

Os répteis podem apresentar comportamentos em relação as estradas de modo a colocá-los em situações de vulnerabilidade, para este grupo, pode ser citado o tipo de movimentação lenta e o comportamento de se aquecer na pista de rolamento para executar termorregulação como fatores que podem justificar os índices de atropelamento (Laurance et al., 2009). Ainda se tratando do grupo dos répteis, as serpentes foram as mais afetadas, somando 11 do total de 18 registros. Em sua grande maioria os atropelamentos são acidentais, muitas vezes motivados pela alta velocidade onde não se têm um tempo para desviar dos animais (Rodrigues et al., 2002). Entretanto, segundo Vale (2017), quando os atropelamentos compreendem serpentes, alguns são de natureza intencional, pois motoristas apontam o veículo de encontro ao animal para os atingirem, e a maioria dos motivos para que isso aconteça estão vinculados ao medo e os riscos inerentes dos venenos e do perigo eventual 
representado pelas serpentes.

Do total de 41 carcaças encontradas 30 encontravam-se na pista e somente 11 no acostamento, o que pode explicar os números de reatropelamento pois 27 das 41 foram reatropelados e somente 14 não, notou-se também com os resultados da pesquisa que a maioria das carcaças não apresentavam urubus ou gaviões se alimentando das mesmas, somente em 05 delas foi possível observar esse comportamento, talvez pelo fato de a grande maioria se encontrar ainda na pista tendo o frequente deslocamento de veículos impossibilitando assim a chegada desses animais carniceiros (Figura 4 ).

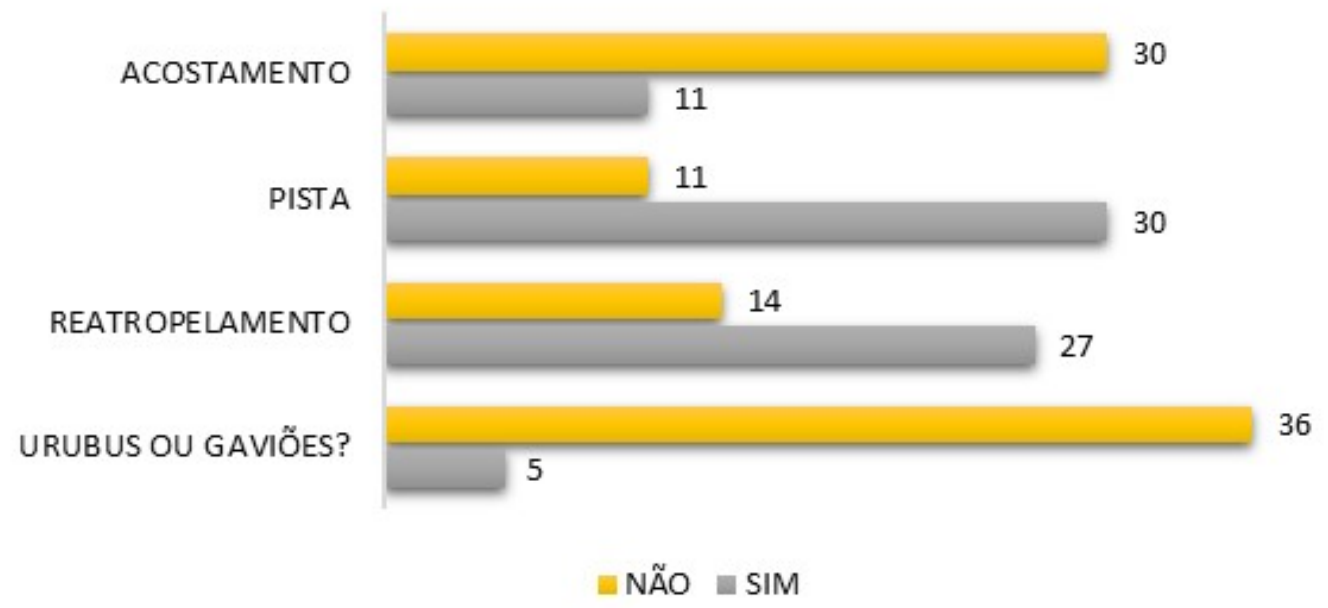

Figura 4 - Variação do número de carcaças na pista ou acostamento, números de reatropelamentos e presença de urubus ou gaviões.

\section{Variação sazonal dos atropelamentos}

Entre a estação considerada com um menor número de chuva para este trabalho de acordo com dados do Laboratório de Meteorologia da UEMA LabMet (2019), estão os meses de janeiro com aproximadamente $220 \mathrm{~mm}$ de precipitação pluviométrica média acumulada e fevereiro com aproximadamente $340 \mathrm{~mm}$, já a estação considerada com um maior número de chuva estão os meses de março com $400 \mathrm{~mm}$, abril com $420 \mathrm{~mm}$ e maio com $300 \mathrm{~mm}$. Durante esse período não foi encontrada diferença na taxa mensal de atropelamento para mamíferos e anfíbios, já o grupo das aves apresentou um número maior de incidência nos meses com menor número de chuva, para os répteis o número maior de incidência ocorreu nos meses de maior número de chuvas, como mostra a Figura 5.

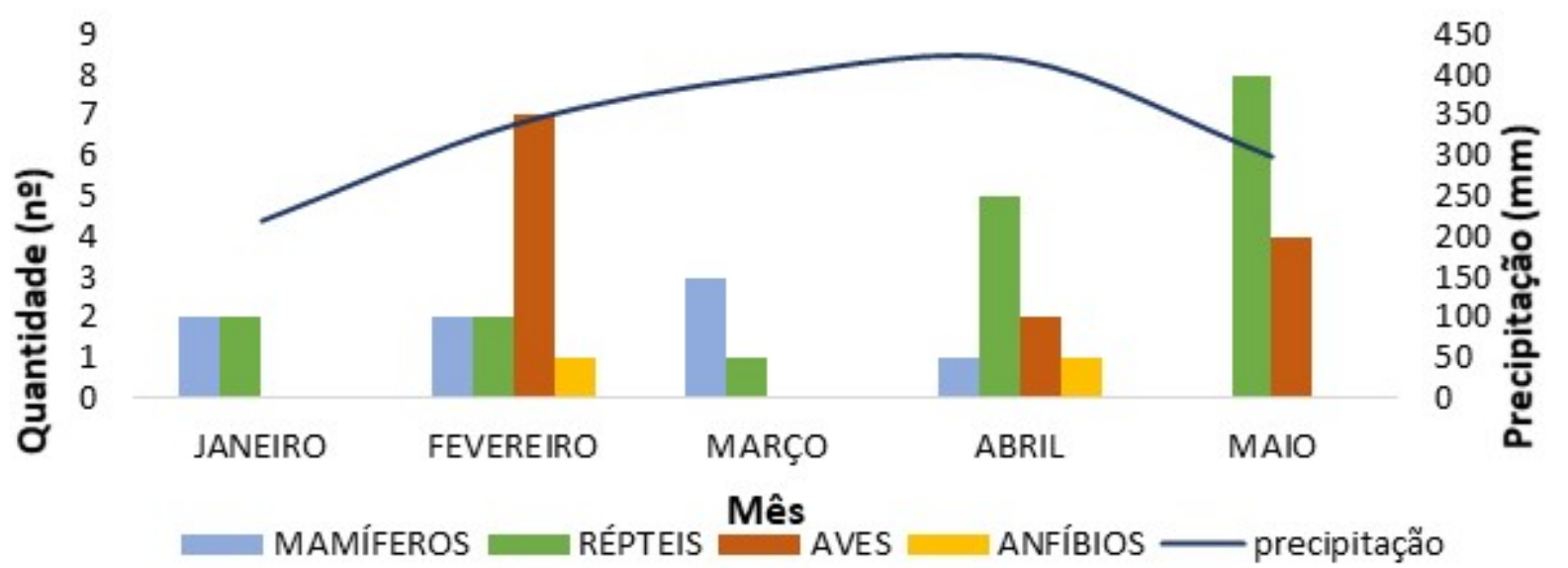

Figura 5 - Variação sazonal de todos os vertebrados atropelados na Rodovia Estadual MA-106, trecho que liga os municípios de Santa Helena e Pinheiro, de janeiro de 2019 a maio de 2019. 
Embora haja diferenças entre o esforço amostral realizado neste trabalho para com outros já feitos no Brasil, no geral os dados referentes a sazonalidade são semelhantes ao trabalho realizado por Carvalho (2014), na BR-050, trecho de Uberlândia - Uberaba/SP, onde em um ano de pesquisa foram encontrados 683 vertebrados mortos por atropelamento, constatou que para mamíferos e aves não houve diferença na taxa mensal de atropelamentos, para répteis foi identificado diferença na taxa mensal de atropelamentos entre as estações secas e chuvosas, sendo a estação chuvosa a de maior ocorrência. Miranda (2007), em seu trabalho na rota de acesso aos Lençóis Maranhenses no estado do Maranhão destacou que as ocorrências de atropelamentos registradas foram nos primeiros meses também mais chuvosos do ano sendo o grupo dos anfíbios e répteis os mais vitimados.

Milli e Passamani (2006), destacam em seu trabalho na Rodovia Josil Espíndula Agostini (ES-
259) que, em todos os meses do ano animais são atropelados, tendo um ligeiro aumento nos meses de junho e julho e um decréscimo em setembro. Almeida e Cardoso (2014), constatam que a maior taxa de ocorrência de atropelamento no período chuvoso pode estar ligada ao fato de que esses animais nesse período se deslocam mais sobre a pista para eventos de dispersão e reprodução, principalmente répteis e anfíbios, com altas taxas de atropelamento.

\section{Medidas para mitigar os atropelamentos}

O georreferenciamento apresentado na figura 6 pode se tornar uma ferramenta valiosa para se estabelecer medidas mitigadoras, pois com seu auxílio pode-se verificar em quais pontos e trechos da rodovia encontram-se as maiores agregações e casos de atropelamento da fauna silvestre onde cada ponto representa um animal morto por atropelamento.

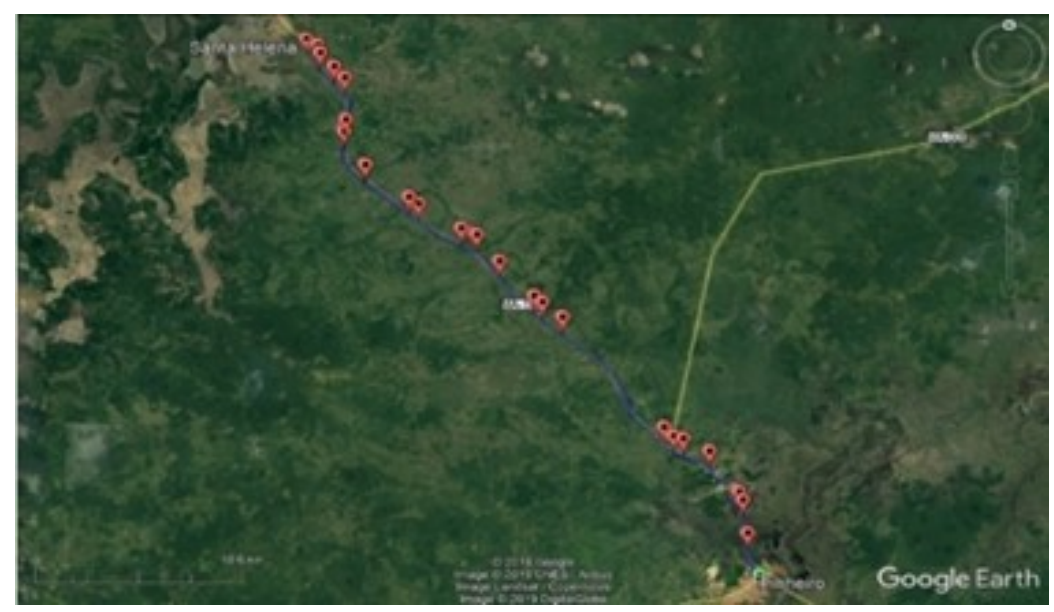

Figura 6 - Georreferenciamento dos animais silvestres encontrados atropelados na Rodovia Estadual MA-106, trecho que liga os municípios de Santa Helena e Pinheiro, de janeiro de 2019 a maio de 2019.

A mais apropriada passagem para a fauna deve levar em conta a paisagem, o tipo de habitat e as espécies de fauna e flora locais bem como os pontos de maior incidência de atropelamentos. Dentre as medidas mais citadas na literatura destacam-se a introdução tuneis, passarelas e galerias de longa distância para passagem dos animais e a introdução de cercas ao lado da pista para dificultar a passagem dos animais, a utilização de duas ou mais medidas mitigadoras juntas, aumentam consideravelmente a eficiência na prevenção de colisões entre os animais e os veículos (Zanardo, 2018). No Brasil algumas dessas medidas vem sendo implantadas em rodovias ao longo dos anos como mostra Abra (2012), em sua revisão sobre o tema, o Departamento Nacional de Infraestrutura de Transportes DNIT, vem realizando estudos e implantando medidas mitigadoras em rodovias do país desde 1998. Como exemplos apresentados nas figuras 7 . 

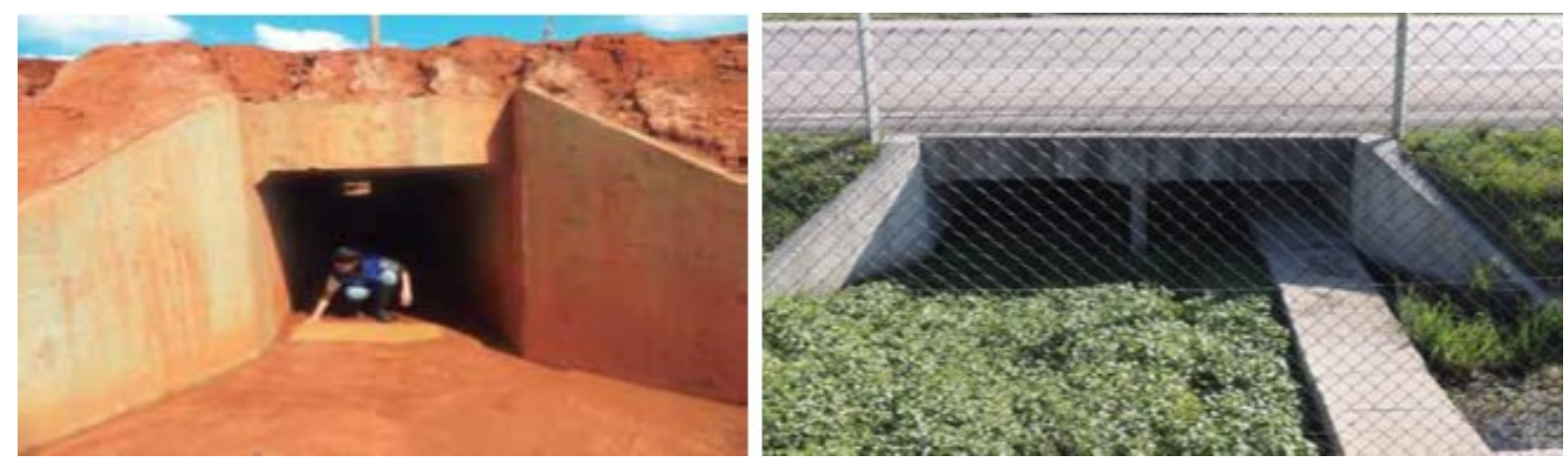

Figura 7 - Exemplos de passagem para fauna, I) passagem tipo caixa; II) Passagem de fauna subterrânea mista na rodovia BR-392/RS.

Medidas como essas veem contribuindo para a diminuição de animais mortos por atropelamento na Reserva Ecológica do Taim no Rio grande do Sul na BR-471/RS, onde no ano de 2012, 375 animais morreram atropelados na rodovia já no ano de 2017 apenas 63 animais perderam a vida na estrada. Desde 1996 em parceria com o IBAMA e ICMBio o Departamento Nacional de Infraestrutura de Transportes (DNIT), vem implementando um sistema de proteção à fauna, foram instaladas passagens de fauna e telas direcionadoras a fim de impedir atropelamentos, sinalização educativa e de advertência aos motoristas e redutores de velocidade nos trechos sem telamento (DNIT, 2012).

Dentre muitas dessas medidas já destacadas neste estudo talvez a mais importante seja a Educação Ambiental, como ressalta Narcizo (2009), tendo em conta que se deve atuar localmente no intuito de se alcançar soluções que favorecerão a todos.

Medidas de Educação Ambiental são indispensáveis para reduzir os índices de atropelamento nesta área de estudo, seria necessário primeiramente que se instalasse placas de sinalização ao longo da rodovia ou nos pontos de maior incidência de atropelamentos, os redutores de velocidade podem ser uma alternativa, assim como a necessidade de se ter maneiras para a sensibilização dos motoristas como divulgação na mídia por exemplo.

Para Oliveira e Latini (2013), em rodovias, o acesso ao público-alvo se torna mais difícil para trabalhos de Educação Ambiental. Desse modo, o acesso pode ser através de blitz promovidas pela Polícia Rodoviária ou Florestal, com distribuição de materiais didáticos em pedágios e em postos de abastecimento. A implantação de outdoors com elementos informativos pode representar grande contribuição para chamar a atenção dos motoristas para o problema e para enfatizar informações importantes (Rodrigues e Colesanti, 2008). Como no exemplo da figura 8 , onde foram instalados outdoors em locais com maior índice de atropelamentos na BR116 em Santa Catarina (ND, Florianópolis, 2015).

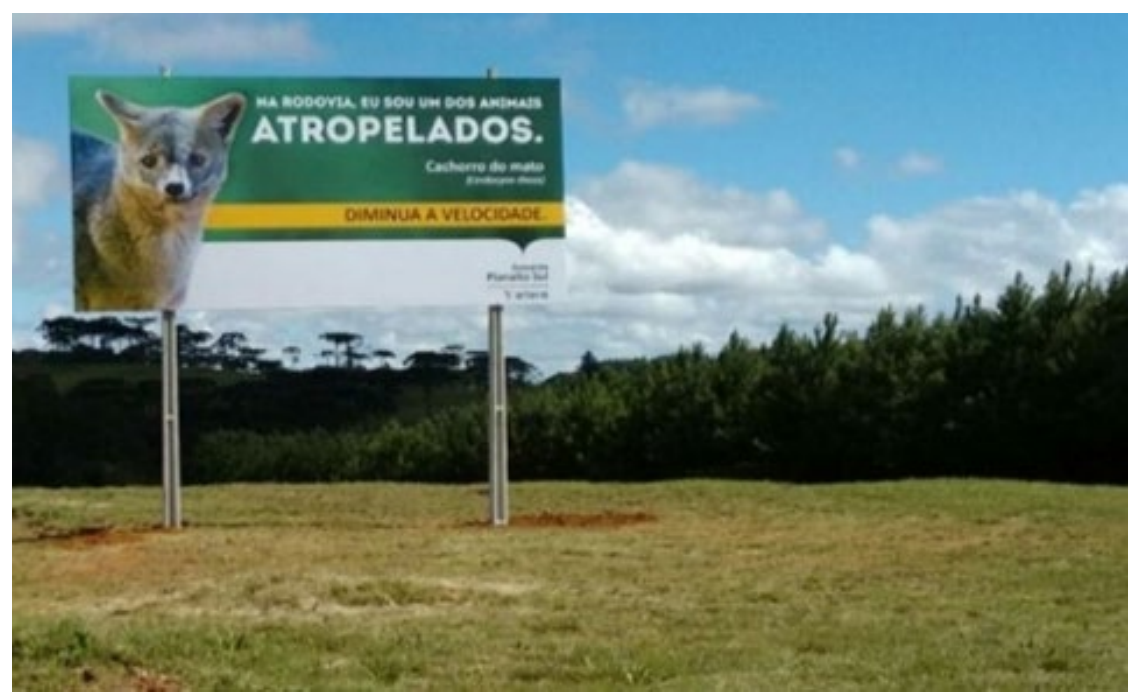

Figura 8 - Exemplo de outdoors com elementos informativos em trechos da BR-116. 
Esse tipo de estratégia é muito importante, no tocante ao trazer conhecimento sobre o problema, podendo promover a sensibilização e conscientização do público alvo (Oliveira e Latini, 2013).

Assim, percebe-se que estudos de maior duração na área abrangida por este trabalho são de suma importância, para que se possa estabelecer medidas funcionais para mitigar os atropelamentos. $\mathrm{O}$ georreferenciamento das carcaças encontradas e a sazonalidade discutidas nesse trabalho são importantes para que se conheça os pontos onde se concentram o maior número de acidentes com os animais e os meses de maior incidência.

\section{CONCLUSÕES}

Os resultados obtidos com este estudo corroboram com a literatura ao confirmar o grande impacto das rodovias sobre o ambiente natural, pois $\mathrm{o}$ número da fauna silvestre morta por atropelamento, registrado por este trabalho é significativo. A classe dos répteis foi a mais afetada com $18(43,90 \%)$ dos registros e 06 espécies, seguida da classe das aves com $13(31,71 \%)$ dos registros e 06 espécies, a terceira classe mais afetada foi a dos mamíferos com $8(19,51 \%)$ dos registros e 02 espécies, a última e a classe menos afetada foi a dos anfíbios com $02(4,88 \%)$ dos registros e 02 espécies. Por fim, após análise dos dados coletados, nota-se que certas medidas de mitigação podem ser implantadas para minimizar os atropelamentos, como por exemplo uma sinalização de fauna adequada, meios que dificultem a travessia de animais nas rodovias e dispositivos facilitadores de travessia de fauna.

\section{REFERÊNCIAS BIBLIOGRÁFICAS}

Abra FD. Monitoramento e avaliação das passagens inferiores de fauna presentes na rodovia SP-225 no município de Brotas, São Paulo. 2012. 72 f. Dissertação (Mestrado em Ecologia de ambientes aquáticos e terrestres). Universidade de São Paulo. 2012.

Almeida VM, Cardoso Júnior JCS. Registros de atropelamentos de animais silvestres na rodovia vicinal Antônio Joaquim de Moura Andrade entre os Municípios de Mogi Guaçu-sp e Itapira-SP. FOCO - Ano 5 - no 7 - Julho/Dezembro 2014 .

Bandeira C, Floriano EP. Avaliação de impacto ambiental de rodovias. Caderno Didático n. 8. Santa Rosa. 2004.

Bager et al. Os caminhos da conservação da biodiversidade brasileira frente aos impactos da infraestrutura. Biodiversidade Brasileira, v. 6, n. 1, p.75-86, 2016.

Bernarde PS, Machado RA, Turci LCB. Herpetofauna da área do Igarapé Esperança na Reserva Extrativista Riozinho da Liberdade, Acre - Brasil. 2011.
Carvalho CF. Atropelamento de vertebrados, hotspots de atropelamentos e parâmetros associados, BR-050, trecho Uberlândia-Uberaba. 2014. Dissertação (Mestrado em Ecologia e Conservação de Recursos Naturais). Universidade Federal de Uberlândia. 2014.

DNIT. Monitoramento e Mitigação de Atropelamentos de Fauna. Brasília, 2012.

Deffaci et al. Diversidade de aves, mamíferos e répteis atropelados em região de floresta subtropical no sul do Brasil. Ciência e Natura, Santa Maria v.38 n.3, 2016.

Fonseca JJS. Metodologia da pesquisa científica. Fortaleza: UEC, 2002. Apostila.

Hengemühle A, Cademartori CV. Levantamento de mortes de vertebrados silvestres devido a atropelamento em um trecho da estrada do mar (RS-389). Biodivers. Pampeana, v. 6, n. 2, p. 4-10, 2008.

Instituto Brasileiro de Geografia e Estatística - IBGE. IBGE apresenta nova área territorial brasileira: 8.515.767,049 $\mathrm{km}^{2}$. Disponível em: $<$ https://agenciadenoticias.ibge.gov.br/2013-agencia-de-noticias/releases/14318asi-ibge-apresenta-nova-area-territorial-brasileira8515767049-km.html>. Acesso em 04 de setembro de 2018 .

Laurance WF, Goosem M, Laurance SGW. Impacts of roads and linear clearing on tropical forests. Trends in Ecology and Evolution, v. 24, n. 12, p. 659-669, 2009.

LABORATÓRIO DE METEOROLOGIA DA UNIVERSIDADE ESTADUAL DO MARANHÃO. Avaliação Mensal de Chuva. Disponível em: $<$ https://www.nugeo.uema.br/?cat=58>. Acesso em 30 de agosto de 2019.

Maciel R, Machado BG. Guia de Aves. Fundação Ezequiel Dias - Funed. 2013.

Mesquita AS, MORAES PSS. Levantamento de Animais Silvestres Atropelados na Rodovia Br-316, Maranhão, Brasil. 2018.

Ministério dos Transportes. Infraestrutura Rodoviária. Disponível em: <http://www.transportes.gov.br/rodovias-brasileiras.html>. Acesso em: 04 de setembro de 2018.

Milli MS, Passamani M. Impacto da Rodovia Josil Espíndula Agostini (ES-259) sobre a mortalidade de animais silvestres (Vertebrata) por atropelamento. Natureza online 4(2): 40-46. 2006

Miranda JP. Ecologia e conservação da herpetofauna do Parque Nacional dos Lençóis Maranhenses, Maranhão, Brasil. Tese de Doutorado. Universidade Estadual de Campinas UNICAMP. Campinas. 2007.

Narcizo KRS. Uma análise sobre a importância de trabalhar Educação Ambiental nas Escolas. Revista Eletrônica do Mestrado em Educação Ambiental. ISSN 1517-1256, v. 22, janeiro a julho de 2009.

Oliveira PB, Latini RO. Educação Ambiental: Uma abordagem para minimizar os atropelamentos da fauna silvestre. Acervo da Iniciação Científica. 2013.

Prada CS. Atropelamento de vertebrados silvestres em uma região fragmentada do nordeste do estado de São Paulo: quantificação do impacto e análise de fatores envolvidos. São Carlos: UFSCar, 2004 
Paes CM, Povaluk M. Atropelamento de Animais Silvestres na Rodovia Federal Br-116, Trecho Administrado pela Concessionária Autopista Planalto Sul. Saúde Meio Ambiente. v. 1, n. 2, dez. 2012.

Redação ND, Florianópolis. Para diminuir atropelamento de animais, empresa instala placas gigantes em rodovia de SC Disponível em: < https://ndmais.com.br/noticias/para-diminuir-atropelamento-de-animais-empresa-instala-placas-gigantes-em-rodovia-de-sc/>. Acesso em: 16 de junho de 2019.

Rodrigues FHG, Hass A, Rezende LM, Pereira CS, Figueiredo CF, Leite BF, França FGR. Impacto de rodovias sobre a fauna da Estação Ecológica de Água Emendadas, DF. In: Anais do III Congresso Brasileiro de Unidades de Conservação, Fortaleza/CE,Brasil, 2002. p. 585.

Rodrigues GSSC, Colesanti MTM. Educação ambiental e as novas tecnologias de informação e comunicação. Sociedade e Natureza, Uberlândia, v. 20, n. 1, p. 51-66, jun. 2008.

Roth PG, Scott DA. A avifauna da Baixada Maranhense. IN: BRASIL. Secretaria Especial de Meio Ambiente/ Internacional Waterfowl Research Bureau-IWRB/ Companhia Vale do Rio Doce. 1427 Machado.M.A.; Pinheiro.C.U.B. 1987.

Santos ALPG, Rosa CA, Bager A. Variação sazonal da fauna selvagem atropelada na rodovia MG 354, Sul de Minas Gerais - Brasil. Universidade Federal de Lavras, Biotemas, v. 25, no 1, p. 73-79, mar. 2012.

Sant'Ana WC. Contribuição ao estudo de solo-emulsão em pavimentos de rodovias de baixo volume de tráfego para o Estado do Maranhão. Tese de Doutorado. Universidade de São Paulo, 2009.

Transportes no Maranhão. 2000. disponível em: $<$ http://www.geipot.gov.br/cadernos/2000/ma2000.htm\#sub13>. Acesso em: 04 de setembro de 2018.

Trombulak SC, Frissell CA. 2000. Review of ecological effects of roads on terrestrial and aquatic communities. Conservation Biology, 14(1): 18-30.

Vale MAA. Intencionalidade do atropelamento de Oxyrhopus trigeminus (Reptilia: Serpentes) na Rodovia MA-230 no município de Chapadinha, Maranhão. Monografia. Universidade Federal do Maranhão. Chapadinha, MA. 2017.

Zanardo GLP. Construção de passagens de fauna em rodovias para a sobrevivência de animais silvestres. Monografia Universidade Federal do Rio Grande do Sul. Porto Alegre, RS, 2018. 